\title{
La modificación del relato legendario en La mujer pantera, de Jacques Tourneur (1942)
}

Angélica García Manso

Universidad de Extremadura 



\title{
La modificación del relato legendario en La mujer pantera, de Jacques Tourneur (1942)
}

\section{Change and legend in Cat People (Jacques Tourneur, 1942)}

\author{
Angélica García Manso \\ Universidad de Extremadura \\ angmanso@unex.es
}

Fecha de recepción: 8 de octubre de 2018

Fecha de aceptación: 20 de diciembre de 2019

\begin{abstract}
Resumen
El estudio analiza el relato y las fuentes textuales de La mujer pantera (Cat People, 1942), clásica película dirigida por Jacques Tourneur, y se hace a partir de la idea de transformación de una leyenda. Esbozada originariamente por Val Lewton en 1930 , se trata de una leyenda que concede una importancia fundamental al tema de la metamorfosis, como si de un relato mitológico grecolatino se tratara: así, en la conversión de una mujer en pantera ante el contacto carnal masculino se funden una supuesta maldición medieval de raíces eslavas con la reacción furibunda de deidades clásicas al ser descubiertas en su desnudez. El análisis de la variación de un relato legendario en otro diferente posee una palpable utilidad didáctica a la hora de comprender el surgimiento de nuevas narraciones, máxime cuando su soporte es el arte cinematográfico.
\end{abstract}

Palabras clave: Leyenda; Metamorfosis; Aplicaciones didácticas; Iconografía; Historia del Cine.

\footnotetext{
Abstract

This study analyzes the story and textual sources of Cat People (1942), classic film directed by Jacques Tourneur, from the idea of transformation of a legend. This legend was originally outlined by Val Lewton in 1930, and it gives fundamental importance to the theme of metamorphosis, as it was a Greco-Roman mythological tale: thus, the conversion of a woman in a panther with the male sexual contact fuses a supposed Slavic medieval curse with the furious reaction of classical deities when they were discovered in their nakedness. The analysis of the variation of
} 
La modificación del relato legendario en La mujer pantera... - A. García Manso

a legendary story into a different one has a palpable teaching utility in order to understand the emergence of new tales, especially when their support is cinema.

Keywords: Legend; Metamorphosis; Teaching applications; Iconography; History of Cinema.

\section{INTRODUCGIÓN: LOS ORÍGENES DEL RELATO}

El presente estudio aborda el ejemplo de una leyenda en transformación desde sus referentes textuales hacia una nueva caracterización, que aparece en los fotogramas de un filme y, por consiguiente, resulta ya de carácter prevalentemente iconográfico. Si bien no existe una leyenda tradicional concreta que la respalde, la narración sobre la mutación de una mujer en felino se elabora a partir de motivos históricos y fantásticos de índole antropológica, entre los que no faltan paralelismos mitológicos. La transformación que se descubre se caracteriza por transmitirse desde el referente textual (sea o no este ficticio) hasta la creación de unos motivos visuales o de un imaginario, sin los que carecería de sustento la versión emergente del relato, la nueva leyenda, la cual poseerá un sentido diferente a su punto de partida originario. Se trata, en definitiva, de abordar tanto los orígenes de un filme clásico en su base textual como los cimientos de su evolución iconográfica posterior en el Séptimo Arte.

De acuerdo con ello, aun tratándose de un filme de serie B, La mujer pantera (Cat People, 1942), de Jacques Tourneur, es citado como uno de los títulos emblemáticos de la Historia del Cine. Adscrito a un género a caballo entre el relato de misterio y el drama psicológico, su guion y puesta en escena resultan de gran potencia expresiva en torno a una trama de amor imposible a causa de la condena que, de acuerdo con una supuesta antigua leyenda serbia de época medieval, sufre una mujer emigrada a los EEUU que se metamorfosea en felino durante el acto sexual, impidiendo su consumación (Pedraza, 2002; en uno de los estudios de conjunto más relevantes que se han publicado).

Si bien el guion definitivo aparece firmado por DeWitt Bodeen, que fue quien organizó el material de partida -en el que influye también una narración breve del escritor norteamericano Ambrose Bierce (2005) titulada "Los ojos de la pantera", publicada en su primera edición en 1891, cuya protagonista comparte el nombre con el personaje central del filme de Tourneur-, el relato procede en verdad de la labor como escritor del conocido e importante productor de la compañía RKO Val Lewton, responsable, además, de la realización del filme de Tourneur (García Gómez, 2007). Así, entre los textos publicados por Lewton se cuenta Panther Skin and Grapes (1923), un poemario influido por el orientalismo pictórico que fue escrito veinte años antes de la producción del filme; su título alude a la exótica vestimenta de piel de felino junto a unas uvas, una hibridación que, referida a un hombre, recrea la iconografía del dios del panteón clásico Dionisos, y aplicada a una mujer, a 
la seductora figura de una odalisca. En efecto, el enfoque dual del tema de este poemario se va a mantener en otros escritos de Lewton y estará presente en películas producidas por él, como es el caso del filme objeto de análisis, de La mujer pantera.

Es en este contexto en el que se entiende la publicación por parte de Lewton en las páginas de la revista de relatos de terror Weird Tales Magazine correspondiente al mes de julio de 1930 de The Bagheeta, un relato cuyo título evoca, con la mera variación de una letra, el nombre de "Bagheera", la pantera negra que aparece en El libro de la selva, de Rudyard Kipling, publicado originariamente en 1894, y que el escritor británico construyó a partir de la palabra hindi bagh. En la narración de Lewton (1988), ambientada en una inexistente población ucraniana llamada Ghizikhan -nombre, de nuevo, con remarcada influencia oriental, que no se corresponde en realidad con el entorno ruso-, el felino es la reencarnación de una doncella sacrificada que, en venganza, se dedica a aterrorizar la villa y a seducir a sus hombres para matarlos. Únicamente un joven que evite sus encantos podría sobrevivir y vencer al animal cuando se transforme en mujer. Tras organizarse una expedición de batida, el joven protagonista logra matar con su espada al leopardo antes de que se metamorfosee, aunque le queda la duda de si realmente era cierta la leyenda, o de si él mismo no ha hecho sino vivir una experiencia religiosa, de índole cristiana ( $o$, en otras palabras, enfáticamente no pagana), por vencer al mal desde su condición de hombre célibe. Sin embargo, a su regreso y con el fin de ser reconocido como un héroe, el protagonista prefiere vencer su propio escepticismo y opta por variar el relato: él encontró a una joven desnuda bañándose que, al ser descubierta, intentó matarlo, de forma que el personaje habría actuado en legítima defensa, tal como aparece sintetizado el relato en Bansak (1995, pp. 17-20).

Lewton emplea, por consiguiente, tres planos en la leyenda que constituye la base textual que inspira el filme: en primer lugar, el leopardo que se transforma en mujer para engañar a sus víctimas; en segundo lugar, el leopardo que no se transforma y que se comporta como el animal depredador que es; y, en tercer y último lugar, la mujer que se convierte en leopardo al ser descubierta desnuda. De ello se desprende, en lo que se refiere a las metamorfosis propiamente dichas, que la primera transformación implica una culpa del pasado (de donde procedería la leyenda que da origen al relato), en tanto la tercera supone una reacción desde el tiempo presente del personaje (tiempo que genera una nueva leyenda como resultado final del relato). El punto en común entre la supuesta leyenda antigua y la leyenda que forja el personaje se encuentra en el relieve que se concede al sexo: la seducción frente a la castidad.

De esta manera, desde una perspectiva sexual la primera interpretación del texto se centra en el atractivo de la mujer que, en calidad de femme fatale, destruye a los varones que encuentra en su camino, de acuerdo con los parámetros establecidos para el mito, entre otros, en García-Manso (2006). Por su parte, la segunda clave deviene más terrible y próxima al motivo clásico del mito de Diana y Acteón, aunque 
acabe no con la muerte del hombre sino con la de la mujer, según la premisa feminista establecida en DeLauretis (2012).

Ambas ideas en torno a la transformación en The Bagheera se harán presentes de una manera singular en el filme La mujer pantera y, con posterioridad, también en su secuela, titulada La venganza de la mujer pantera (The Curse of the Cat People, 1944), dirigida por Robert Wise y G. von Fritsch. De esta forma, a pesar de que uno y otros filmes no responden a un calco literal del relato, el trasfondo se presenta comprensible y, sobre todo, permite interpretar la forma en que se construyen, recrean y renuevan leyendas, en un proceso del que se desprende una importante herramienta hermenéutica y con fines didácticos. De hecho, décadas después el filme de Tourneur se convierte en referente metacinematográfico no sólo por ser recuperado en el sui generis remake filmado por Paul Schrader en 1982, El beso de la pantera (Cat People), sino como el relato que desde el capítulo primero de la novela El beso de la mujer araña, del escritor argentino Manuel Puig (1976), permite ubicar el escenario de los dos protagonistas, además de ofrecerse como nítido ejemplo de influencia del cine sobre la literatura, en una novela que también fue adaptada al cine con el mismo título en 1985, dirigida por el cineasta brasileño Héctor Babenco (García-Manso, 2012, p. 90).

Con tales premisas es nuestro propósito recorrer los hitos históricos, temáticos, mitológicos e iconográficos que jalonan la transformación desde un relato de seducción colectiva a otro de terror individual. Se trata de hitos que organizan los próximos epígrafes a través de la transformación del relato textual a otro eminentemente visual, como corresponde al arte de la imagen que es el cine.

\section{GONTEXTO DEL FILME: MOMENTO HISTÓRICO DE LA PRO- DUCGIÓN Y REFERENTES FÍLMICOS}

Val Lewton era ruso de nacimiento, aunque con apenas dos años de edad, se trasladó con su familia a los Estados Unidos, de forma que, en realidad, los recuerdos que tenía sobre sus orígenes eslavos no eran directos, sino filtrados a través de los relatos familiares. De ahí la absoluta libertad con la que en su obra de ficción recrea ambientaciones en la Europa Oriental, legitimado por sus orígenes rusos, pero sin un contacto auténtico con el entorno. A este respecto, la elección del nombre de la protagonista como Irena Dubrovna alude a una de las variantes eslavas - propiamente yugoslava- del antropónimo Irene -Irina, en ruso-, en tanto que el apellido responde a un topónimo bielorruso. Por otra parte, ya en el caso específico de La mujer pantera, trasladar la acción a un Nueva York contemporáneo supone enfrentar su borroso pasado con su presente a la vez que contraponer un mundo ancestral con la modernidad; también, y de ahí el carácter polisémico del relato, confrontar ambientes salvajes de animales en libertad con un reino animal reservado a parques y zoológicos, según puede leerse en el estudio de conjunto de Nemerov (2005). 
De esta forma, la leyenda emergente en el cine se cimenta en la contraposición de espacios (evocados y reales), tiempos (antiguos y contemporáneos) y de relación con la naturaleza, tal y como los ejercicios fílmicos Tarzán (The Ape Man, 1932) o King Kong (1933), entre otros, habían abordado con anterioridad al filme de Tourneur.

Es más, tanto desde la perspectiva social (por la maldición que recae sobre un colectivo de mujeres) como desde la psicológica (el temor de una mujer concreta), La mujer pantera responde a pautas ya establecidas en la Historia del Cine y en la relación que el Séptimo Arte mantiene con el psicoanálisis freudiano, como postula García Gómez (2007, pp. 277-280). En el primer caso tales pautas vienen dadas por el corpus de películas producidas por la Universal en la década de los años treinta, entre las que destacan por su relación temática con la película de Tourneur Drácula (1931), de Tod Browning, y El hombre lobo (1941), de George Waggner, en las que las metamorfosis y la procedencia eslava están presentes. Y en lo que se refiere a la influencia del psicoanálisis en el cine destaca el ámbito de los sueños, donde la idea de transformación está presente de nuevo, incluso con una importante aportación de carácter surrealista en la que prima lo onírico (también presente, de forma sutil, en La mujer pantera). En otras palabras, el peso que adquiere la leyenda en el filme responde también a unos parámetros establecidos en la Historia del Cine en el Hollywood de los años treinta y más en concreto del género de terror.

Por lo demás, desde un punto de vista propiamente histórico, el hecho de que el rodaje del filme coincidiera con la II Guerra Mundial no deja de evocar, aunque de forma indirecta, la llamada "Gran Guerra", precisamente en la que Serbia ocupó un papel clave en el desarrollo y la resolución del conflicto, así como en la migración de población desplazada hacia Estados Unidos. En efecto, el carácter guerrero del pueblo serbio aparece plásticamente en los fotogramas asociado a momentos históricos previos, de aire medieval aunque indefinidos de cara a relativizar la propia datación de la leyenda en un entorno europeo en profunda transformación histórica y mutación política.

El espectador percibe, pues, un proceso de extrañamiento -por recurrir al término eminentemente literario- ante un tema que le resulta foráneo, a partir de una situación presente no sólo en los planteamientos temáticos sugeridos por Lewton, sino encarnada también en la figura del propio director, Jacques Tourneur, otra personalidad desplazada y nacionalizado estadounidense al final de la I Guerra Mundial, antes de empezar a trabajar como cineasta en su Francia natal, conforme recoge de forma pormenorizada en su estudio Henry (1973). En efecto, al margen de Lewton, el mismo Tourneur ofrece en su filmografía continuos ejemplos de perplejidad, caso de Retorno al pasado (Out of the Past, 1947), rica en traslados de lugares y tiempos, según han estudiado Fujiwara (2000) o, ya en un ámbito español, Ciompi et alii (1988). 


\section{ESTRUCTURA Y VARIACIONES EN LA MUJER PANTERA: LA LEYENDA QUE ENGENDRA LEYENDA}

La película se estructura en función de las recurrencias que en su interior plasman textos escritos, imágenes, motivos iconográficos y el relato oral, sea de las intervenciones de los personajes o presentado este como voz extradiegética que lee los intertítulos. De alguna manera, tales recurrencias organizan la transformación de la leyenda primigenia, sometida a cambios y variaciones en el propio filme, de forma que el texto genera una nueva leyenda, tal y como se ha apuntado ya en la descripción que hemos efectuado a propósito del relato The Bagheeta. La leyenda emergente se organiza a partir de dos claves: de un parte, la reproducción de los elementos foráneos (una mujer extranjera, enigmáticos dibujos, pinturas y esculturas, un relato de índole tradicional) y se transforma una vez que la protagonista intenta integrarse en la normalidad para dar lugar a una segunda lectura, relativa a cómo la sugestión creativa provoca la destrucción de su artífice; es decir, y de otra parte, a cómo la pintora protagonista invoca su conversión en felino precisamente a partir de las mismas pinturas de felinos que ella dibuja y que hacen avanzar el relato al igual que el viento esparce las hojas del cuadernillo de dibujos donde aparecen plasmadas.

En cuanto a la primera leyenda, la directamente heredada del texto, los títulos de crédito que abren el filme resultan de relieve y se presentan sobre un biombo decorado con la pintura de una pantera negra. Tal fondo varía y centra su foco en una escultura ecuestre de carácter histórico, momento en el que se muestra en pantalla una cita de "The Anatomy of Atavism", obra ficticia, inexistente fuera del relato, como libro cuya autoría se atribuye al personaje de Louis Judd, uno de los protagonistas del filme. El texto dice así: "Como la niebla permanece tendida en los valles, también los pecados antiguos se anclan a los suelos de los lugares, las depresiones

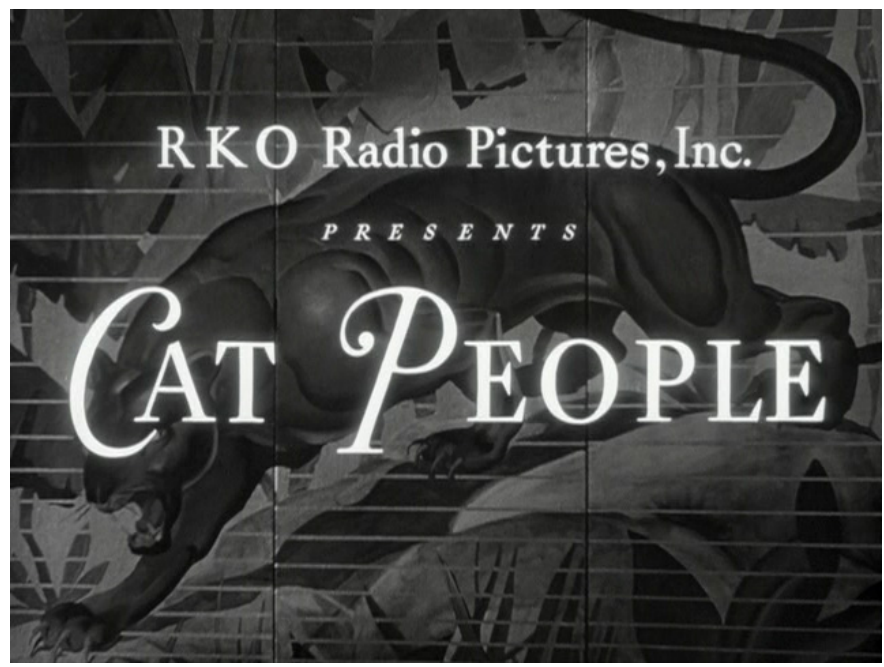
en la conciencia del mundo". Tres ámbitos son, pues, los sugeridos desde el principio de la película: una ambientación borrosa (niebla, oscuridad, sombras), el peso del pasado y, finalmente, la incertidumbre de índole propiamente psicológica. Teniendo en cuenta que se trata de la hipotética cita de un libro sobre atavismo, 
es decir, sobre la pervivencia de actitudes y mentalidades arcaicas en sociedades contemporáneas, la cita expresa en principio una lectura de cariz evemerista, en tanto en cuanto se busca un sentido racional al misterio. Pero se hace sobre la iconografía del biombo, esto es, de un objeto que sirve para velar, y sobre una pequeña pieza escultórica, la misma que aparecerá a contraluz en las dependencias de la protagonista hasta que finalmente se desvele su sentido al tiempo que se relata la leyenda. En efecto, la figura es la de un rey serbio medieval, el rey Juan, vencedor frente a los mamelucos turcos, los cuales aparecen encarnados en una pantera ensartada con su lanza.

La primera escena propiamente dicha, tras los créditos del filme, muestra a Irena, la protagonista, intentando dibujar a una pantera en el zoo. El viento revelará uno de los dibujos en el cuaderno: una pantera atravesada por una espada, elemento presente en la escultura que aparece en los créditos, según se acaba de apuntar. La influencia iconográfica resulta clave a la hora de plantear internamente la leyenda hasta que ésta sea expresada de palabra por parte de la protagonista: durante la invasión mameluca las mujeres no sólo no hicieron frente a los enemigos, sino que se liberaron sexualmente ante los guerreros extranjeros, y, así, ella desciende de esa estirpe de mujeres serbias entregadas a extraños y condenadas por ello a metamorfosearse en felinos en contacto con el hombre que les despierta deseo sexual, con su consiguiente miedo a perder el control en la relación carnal.

Cuando Irena intente normalizar su situación lo hará de forma incompleta, sea mediante un matrimonio que no consuma o mediante su consulta médica al psiquiatra

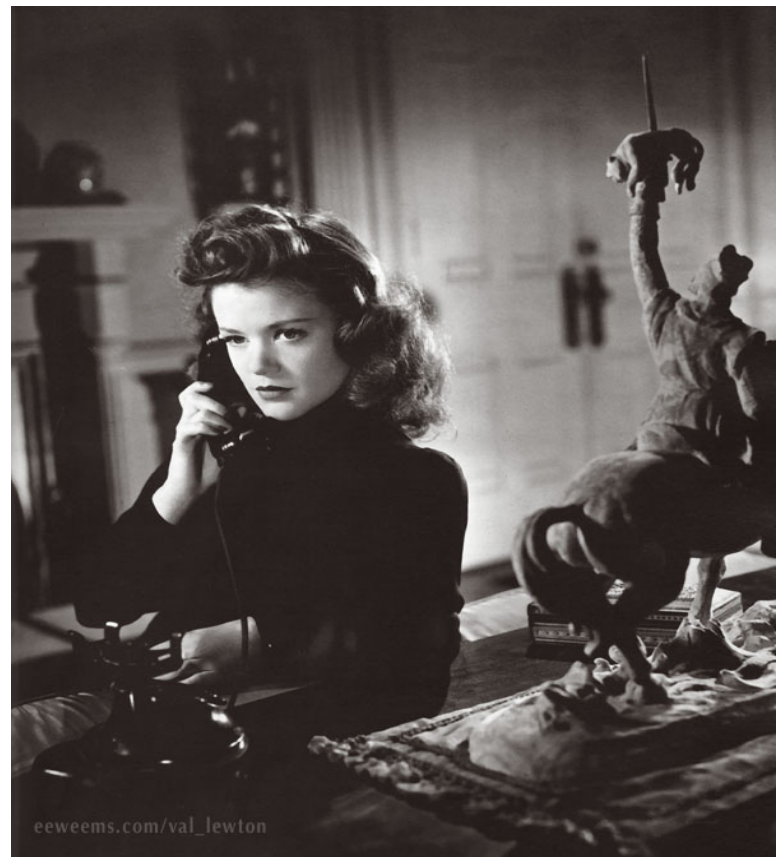
Judd. Es entonces cuando adquieren fisicidad en el relato los temas iconográficos y orales de la primera parte del filme, en forma de sombras, de ruidos, de roces, que convierten en amenazas latentes lo que pintura, escultura e historia evocaban del pasado, y que se hacen patentes cuando sea el mismo Doctor Judd quien intente forzar a Irena. De esta manera, las mujeres que son sujetos en la primera leyenda se convierten en objeto en la segunda como víctimas. La protagonista había invocado como sujeto su condición de pantera, con el biombo, la escultura y los dibujos de 
los que es ilustradora - con motivos inspirados en Arthur Rackham, según GarcíaGómez (2007, p. 320)-; además, había dado voz a una condena antigua, y, como resultado de todo ello, su propia obra se vuelve contra ella.

Así, Irena huye herida tras asesinar al psiquiatra y, al creerse pantera, busca un refugio/prisión en el zoo, donde la pantera auténtica la mata, al tiempo que ésta última escapa y es arrollada por un vehículo, en una sucesión dramática de muertes encadenadas.

La transformación de la leyenda se ve culminada con una nueva cita textual que funciona como réplica a la referencia inicial en torno al atavismo. La cita de los créditos finales procede de los Holy Sonnets de John Donne: “Al cabo, el oscuro pecado fue delatado en la noche profunda, y mi mundo, mi dualidad, uno y otro, deben desaparecer". Es decir, la pantera creada y la real han de morir, toda vez que no hay otra salida posible, que ésta sucede, como en la tragedia clásica, "ex machina" (el camión de la escena final, que arrolla al felino que acaba de escapar del zoo, constituye así la machina clásica).

\section{LA MUTAGIÓN EN TRAGEDIA PSICOLÓGICA DE LA LEYENDA Y LOS REFERENTES MITOLÓGICOS}

Por consiguiente, de acuerdo con el final del filme, es la tragedia la que cierra el ciclo de la leyenda primigenia al tiempo que la transforma, como si de una metamorfosis dentro de la metamorfosis se tratase. El punto inicial de la transformación se encuentra en el relato originario de Val Lewton a partir de un imaginario geográficamente ubicado en una Serbia a caballo entre el mundo occidental y el oriental y entre la historia mameluca y la voluntad de integración en la contemporaneidad posterior a la Gran Guerra, pero en el filme de Tourneur dicho relato adquiere un tratamiento iconográfico orientado ad personam, lo que confiere singularidad al ejercicio fílmico.

La variación se aprecia perfectamente en la oposición que se da entre el tema de la lascivia frente al de la castidad. En efecto, el motivo dionisíaco de la piel de pantera y la forma de expiar el pecado del pasado está presente en The Bagheeta y en el poemario Panther Skin and Grapes, escrito con anterioridad: la piel de pantera se asocia a la danza, al menadismo -entre los animales que poseen a las mujeres en trance se cuentan las panteras- y a los cortejos de Dionisos y Orfeo, pero también el argonauta Jasón porta una piel de felino, según aparece documentado en, por ejemplo, Andrés (2012, p. 1312). En el extremo opuesto, en el filme la aceptación de la castidad por parte del marido en tanto que Irena resuelve su desorden psicológico tiene modelos en la mitología, caso, por ejemplo, de las figuras de Dafnis y Cloe, pero más importantes aún son otros elementos que definen la relación: una extranjera, un ingeniero naval -que viene a ser el trasunto de un marinero en tierra-, la piel como elemento icónico y el temor al abandono remiten al mito de Medea y Jasón 
(aunque sin hijos de por medio). De alguna manera, el relato mitológico funciona como prevención.

Y es que una de las claves que definen la figura mitológica de Medea es la de la extranjera (al menos en el filme de Tourneur, toda vez que en el relato originario de Lewton los extranjeros son los invasores turcos). Pues bien, Irena es una extranjera que teme hacer daño por su condición de bárbara, una condición asumida (de ahí que evite el contacto sexual), que identifica sus orígenes con un animal (en equivalencia con el vellocino del relato clásico) y que encuentra su pareja en el entorno marino (no en vano su marido es ingeniero naval, como también Jasón está relacionado con la navegación).

La forma de evitar el cumplimiento de la leyenda, que acaba dramáticamente dado que el destino de las mujeres pantera es el de asesinar a sus compañeros sexuales, consiste en invertir la figura de la víctima, asumiendo toda la culpa como forma de impedir la continuación de la estirpe. En la nueva leyenda encarnada en el filme se logra el final de la maldición: ella misma muere por causa de una pantera, la cual, a su vez, muere arrollada ex machina en las calles, estableciéndose así el fin de un ciclo.

Esta nueva leyenda supone el punto final de la supuesta condena ancestral. Además, el cierre de la leyenda tiene lugar en los Estados Unidos, en calidad de nuevo entorno y nueva realidad en la que no caben sentencias antiguas, al tiempo que devuelve al ámbito poético (de ahí la cita final de los versos de John Donne) el sentido del relato. La clave formal radica en cómo la nueva leyenda solamente tiene sentido en el relato cinematográfico gracias a las imágenes (dibujos, esculturas, sombras, etcétera).

\section{CONCLUSIÓN: LA ICONOGRAFÍA COMO MOTOR DE TRANS- FORMACIÓN NARRATIVA}

Tres han sido los aspectos sucesivamente abordados en torno a la leyenda de la figura de la mujer pantera: las fuentes textuales (de Kipling y Bierce a Lewton), el tratamiento del relato legendario (con lo relativo a la invasión mameluca en el pasado de un lado y el papel de Serbia en la historia del siglo XX de otro) y, finalmente, la actualización y mutación fílmicas de dicho relato (con la importancia de las imágenes y el avance desde una leyenda comunitaria (sobre las mujeres serbias) hacia el terror individual que provocan las relaciones sexuales en el personaje femenino.

De acuerdo con el análisis efectuado, resulta importante que Irena, personaje central del filme, sea ilustradora de profesión, pues la aportación de Tourneur al guion de Lewton y DeWitt radica básicamente en crear una atmósfera en la que parezca posible que adquieran entidad real creaciones poéticas (pictóricas en el caso de la protagonista). Así, sobre todo en la primera parte del largometraje, las 
representaciones de la pantera (sea en los dibujos o pinturas, sea en la escultura) ofrecen la iconografía de la leyenda antigua, con una fuerte base mitológica (de la mitología clásica más en concreto), en tanto que los recursos propiamente cinematográficos aparecen potenciados en la segunda parte, cuando la leyenda parece manifestarse en los fotogramas hasta su desenlace trágico y, según se ha mostrado en epígrafes precedentes, al tiempo que se provoca la mutación del relato.

A este respeto, no sólo cabe inferir cómo las representaciones anticipan en el relato -recurso habitual en los textos legendarios, por otra parte-, sino que permiten su transformación. De esta manera, no se trata de la interpretación de un relato que se ofrece como una distinción entre lo onírico y lo real, lo sugestionado y lo palpable, ni en virtud de su carácter polisémico, interpretable desde diferentes perspectivas (siendo una de las más habituales la psicoanalítica), sino de cómo Lewton transforma desde su interior su texto de The Bagheeta al conferir al protagonista la opción de variar los sucesos e, igualmente, transforma desde dentro del filme una leyenda ancestral y foránea con el fin de clausurarla, y lo hace desde una perspectiva trágica precisamente para evitar su pervivencia ${ }^{1}$.

De esta manera surgen dos ejercicios a propósito de la película originaria: en primer lugar, sobre la recreación iconográfica de los motivos de la leyenda, y sobre cómo estos evolucionan en interior del relato. Y, en segundo lugar, sobre la transformación de las leyendas, desde el exotismo hasta la proximidad, desde la condena subjetiva que pasa de generación en generación hasta la tragedia culminada en un único personaje. En ambos sentidos, el filme de Lewton/Tourneur resulta una herramienta eficaz además de formar parte de la Historia del Séptimo Arte con mayúsculas.

Y es que ya no se trata de la ominosa presión de la leyenda atávica (expresada en el ficticio libro del personaje del psicoanalista que intenta, apoyado en una concepción de la mujer también atávica, violar a la protagonista) sino de la dualidad sicológica del ser humano, que, en caso de no aceptarse, conduce a la autodestrucción, según los versos de John Donne. Así, la recreación de ese ser doble se hace a través de imágenes: el original y la representación, el objeto y su sombra, el manual y el poema, la racionalidad de la técnica y la irracionalidad del deseo sexual que la pone en jaque.

1 Ello a pesar de que, en el momento en que se diseña el filme, no está prevista su secuela; será el éxito del tratamiento el que provoque la secuela llamada La venganza de la mujer pantera (The Curse of the Cat People, 1944), dirigida por Robert Wise y Gunther von Fritsch), con un carácter diferente, más iniciático desde el momento en el que el papel fundamental recae en una niña y con un final lejos del realismo con que se cierra el filme de Tourneur. De igual forma, la relectura del original que se hace cuarenta años después, titulada El beso de la pantera (Cat People, 1982), por parte de un director de marcada poética como Paul Schrader, traslada a la prehistoria humana y a un burdel próximo a Nueva Orleans los orígenes de la maldición que plasma en imágenes de fuerte contraste cromático, y donde no hay leyenda en transformación, sino que ésta es confirmada visualmente (según se aprecia también en Paige, 1997). 


\section{BIBLIOGRAFÍA}

Andrés, Ramón (2012). Diccionario de música, mitología, magia y religión. Barcelona: Acantilado.

Bansak, Edmund G. (1995). Fearing the Dark: The Val Lewton Career. Jefferson (North Carolina): McFarland.

Bierce, Ambrose (2005). ¿Pueden suceder tales cosas? Cuentos fantásticos completos. Madrid: Valdemar.

Ciompi, V., M. Marías, T. Partearroyo et al. (1998). Jacques Tourneur. San Sebastián/ Madrid: Festival Internacional de Cine/Filmoteca Española.

De Lauretis, Teresa (2012). Panteridad: vivir en un cuerpo dañad. EU-topias: Revista de interculturalidad, comunicación y estudios europeos, n. 4, pp. 9-18.

Fujiwara, Chris (2000). Jacques Tourneur: The Cinema of Nightfall. Baltimore: The Johns Hopkins University.

García Gómez, Francisco (2007). El miedo sugerente: Val Lewton y el cine fantástico y de terror de la RKO. Málaga: Diputación Provincial.

García-Manso, Angélica (2006). Fuentes del mito de la mujer fatal en El Ángel Azul (Der Blaue Engel, 1930). Norba-Arte, n. 26, pp. 177-200.

García-Manso, Angélica (2012). (Séptimo Arte)². Intertextualidad fílmica y metacine. Madrid: Pigmalión Edypro \& Litecom.

Henry, Michael (1973). Le Jardin aux sentiers qui bifurquent (sur Jacques Tourneur). Positif, n. 149, pp. 14.

Lewton, Val (1923). Panther Skin and Grapes. New Orleans: Poynton Press.

Lewton, Val (1930). "The Bagheeta", Weird Tales Magazine, Jul. 1930 [Kaye, Marvin (Ed.) (1998). Weird Tales: The Magazine that Never Dies. New York: SFBC].

Nemerov, Alexander (2005). Icons of Grief. Val Lewton's Home Front Pictures. Berkeley/ Los Angeles/London: University of California Press.

Paige, Linda Rohrer (1997). The Transformation of Woman: the "curae" of the Cat Woman in Val Lewton/Jacques Tourneur's Cat People, its sequel and remake. Literature Film Quaterly, n. 25, pp. 291-299.

Pedraza, Pilar (2002). La mujer pantera: guía para ver y analizar. Valencia/Barcelona: Nau Llibres/Octaedro. 
